\title{
Rate of Canine Retraction and Anchor Loss During Individual Canine Retraction
}

\author{
Joseph Abraham ${ }^{1}$ and K. K. Shantha Sundari ${ }^{2}$ \\ ${ }^{1}$ Post Graduate Student Department of Orthodontics Saveetha Institute \\ of Medical and Technical Sciences Chennai-600077, India \\ ${ }^{2}$ Professor Department of Orthodontics Saveetha Institute of \\ Medical and Technical Sciences Chennai, 600077 India
}

\section{ABSTRACT}

Aim:The aim of this study is to evaluate the rate of bodily movement of canine during individual canine retraction and the amount of anchor loss with two different methods- elastomeric chains and NiTi coil spring. Materials And Methods: Sample size calculated using GPower software was 14. The patient was randomised according to the lottery method and divided into two groups. Group A had elastomeric chains on the right side and NiTi coil spring on the left and Group B has elastomeric chain on the left and NiTi coil spring on the right side of the quadrant. Elastomeric chain was extended from the molar tube to the canine hook on one side. A $9 \mathrm{~mm}$ NiTi closed coil spring was extended from the first molar to the canine hook on the other side.The rate of canine movement and the anchor loss was measured from the intraoral scan done by 3Shape scanner. The scanned images were superimposed and the distance between the pre and post mesial tip of canine gave the distance moved by the canine. This divided by the number of months gives the rate of retraction. The pre and post canine retraction scanned models were overlapped over each other to measure the amount of anchor loss that occurred during the canine retraction. Results: The rate of canine retraction for elastomeric chains is $3.94 \pm 0.73 \mathrm{~mm}$ and that for NiTi coil spring is $4.69 \pm 0.13 \mathrm{~mm}$. There was a statistical significant difference in the rate of canine retraction between NiTi coil spring and elastomeric chains at T0 and T3 (P value=0.02). The amount of mean anchor loss for elastomeric chain was $2.45 \mathrm{~mm}$ with a standard deviation of 0.27 and the mean anchor loss for NiTi coil spring was $1.99 \mathrm{~mm}$ with a standard deviation of 0.19 and was statistically significant between them. Conclusion: NiTi produced a faster rate of tooth movement than elastomeric chains. Elastomeric chains produced a significant amount of anchor loss when compared to NiTi coil spring.

KEY WORDS: CANINE RETRACTION, NITI COIL SPRING, ELASTOMERIC CHAINS, ANCHOR LOSS.

\section{ARTICLE INFORMATION}

*Corresponding Author: josephkadooparayil@gmail.com Received 5th Aug 2020 Accepted after revision 25th Sep 2020 Print ISSN: 0974-6455 Online ISSN: 2321-4007 CODEN: BBRCBA

Thomson Reuters ISI Web of Science Clarivate Analytics USA and Crossref Indexed Journal

$$
\begin{aligned}
& \text { Clarivate } \\
& \text { Analytics }
\end{aligned}
$$

NAAS Journal Score 2020 (4.31) SJIF: 2020 (7.728)

A Society of Science and Nature Publication,

Bhopal India 2020. All rights reserved.

Online Contents Available at: http//www.bbrc.in/

Doi: http://dx.doi.org/10.21786/bbrc/13.8/178 


\section{INTRODUCTION}

In orthodontic treatment extraction is frequently required to correct crowding and to improve the facial profile and to retract the anterior teeth. The most frequently tooth extracted and the most ideal tooth for correction of bimaxillary protrusion is the first bicuspids. The $7 \mathrm{~mm}$ gained after extraction in each quadrant is utilised for correction of crowding, proclination or for protraction of posterior teeth(Güray and Orhan, 1997). There are two methods of space closure: individual canine retraction followed by retraction of the incisors and en-masse retraction of the entire anterior segment. In individual canine retraction the canine in each quadrant is retracted to make full contact with the tooth distal to the extraction space and fastened to the posterior segment and made as one unit. This is followed by the retraction of the anterior incisor segment. With this method the load on the posterior segment is reduced, thus reducing any undesirable changes to the posterior teeth and reduces the chances of molars moving forward. However, the time needed for space closure is longer and the canines tend to tip and rotate more, thus requiring additional time and effort to relieve and realign the teeth.

Another school of thought is en-masse retraction where the entire anterior segment is retracted as a single unit. Application of optimal force values, continuously and simultaneously over the due threshold is sufficient to retract the canines and the incisors without causing any excessive anchor loss. It can be suggested that the force required to retract the anterior segment dissipates and are below the biological threshold level to cause substantial movement of any posterior segment (Graber et al., 1994). NiTi is a very common auxiliary used for retraction of anterior segment and can be activated to a much greater extent before permanent deformation and they are specially indicted in cases of large extraction spaces or if there are infrequent adjustment opportunities are present(Sharma et al., 2015). They deliver a continuous force till the end of the deactivation stage is reached. The advantage of these spring is that they can be easily placed and removed and do not need reactivation every appointment. But they are relatively unhygienic as compared to elastic modules(Sharma et al., 2015).

Our extensive research expertise ranged from epidemiological studies to randomised clinical trials that have been published in reputed journals (Charles et al., 2018; Chinnasamy et al., 2019; Felicita, 2017a, 2017b, 2018; Felicita et al., 2017; Korath et al., 2017; Krishnan et al., 2017; Pandian et al., 2018; Reddy et al., 2018). This knowledge was instrumental for us to study the rate of canine retraction and anchor loss during individual canine retraction. The aim of this study is to evaluate the rate of bodily movement of canine during individual canine retraction and the amount of anchor loss with two different methods: elastomeric chains and NiTi coil spring.

\section{MATERIALS AND METHODS}

Sample size calculated using GPower software was 14. Patients who were undergoing fixed orthodontic treatment in the department of orthodontics at Saveetha Dental College and Hospital, Chennai were taken for the study. The study was designed to be a split mouth randomised control trial. Patients selected for the study were undergoing fixed orthodontic treatment with 0.022 MBT bracket prescription who needed upper first premolar extraction as part of their treatment plan, and were on $0.019 \times 0.025$ inch stainless steel wire with second molar included and was at the end of levelling and aligning stage. Intra-oral scans were taken using a MEDIT scanner and digital models were analyzed using ORTHOANALYSER software.

Methodology: The patient was randomised according to the lottery method and divided into two groups. Group A had elastomeric chains on the right side and NiTi coil spring on the left and Group B has elastomeric chain on the left and NiTi coil spring on the right side of the quadrant. Elastomeric chains was extended from the molar tube to the canine hook on one quadrant and a 9 $\mathrm{mm}$ NiTi closed coil spring was extended from the first molar to the canine hook on the other side. The posterior segments were held together as one unit by ligating them together. The force generated was calibrated to $200 \mathrm{Gms}$ using a dontrix gauge.

Intra-oral models and photographs were taken every month till the canine space closed on either one side. The rate of canine movement and the anchor loss was measured from the intraoral scan done by 3Shape scanner. The scanned images were superimposed and the distance between the pre and post mesial tip of canine gave the distance moved by the canine (Fig 1 $1 \mathrm{t} 2$ ). This divided by the number of months gives the rate of retraction. The pre and post canine retraction scanned models were overlapped over each other to measure the amount of anchor loss that occurred during the canine retraction (FIG 3\&t4).

Figure 1: Superimposition of pre and post camine retraction models

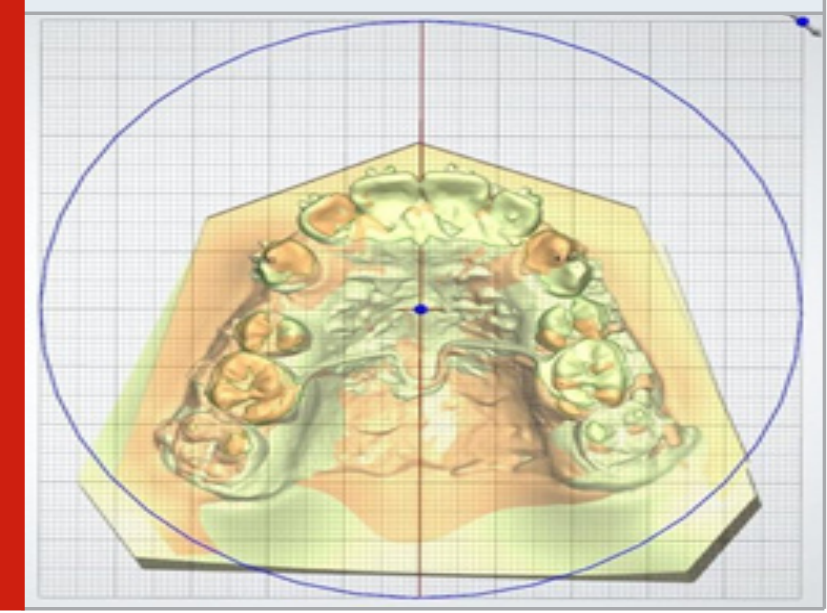




\section{Figure 2: Measurement of camine movement}

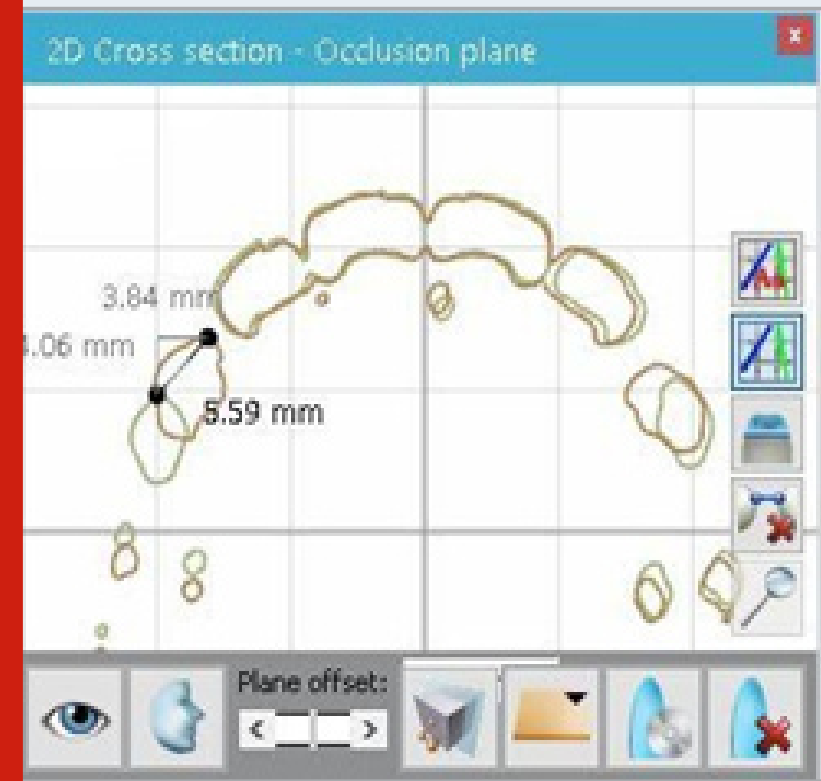

Figure 3: overlapping of pre and post camine retraction models for anchor loss on NiTi spring quadrant

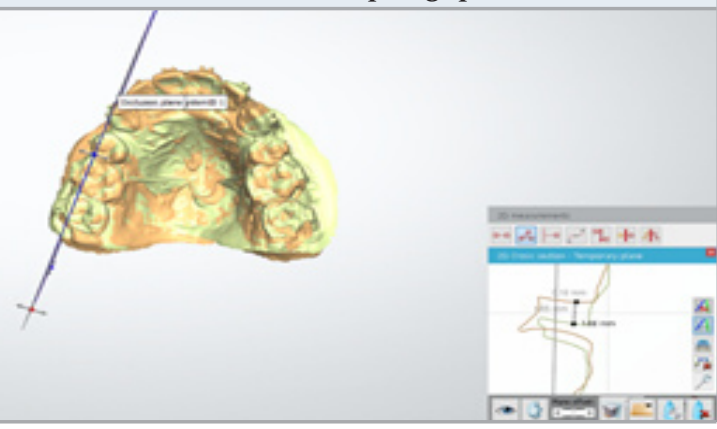

Figure 4: Overlapping of pre and post camine retraction models for anchor loss on elastomeric chain quadrant
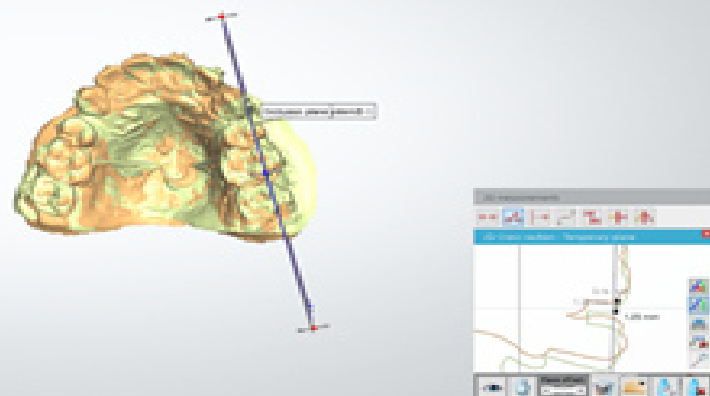

\section{RESULTS}

The rate of canine retraction for elastomeric chains is $3.94 \pm 0.73 \mathrm{~mm}$ and that for NiTi coil spring is $4.69 \pm 0.13 \mathrm{~mm}$. There was a statistical significant difference in the rate of canine retraction between NiTi coil spring and elastomeric chains at T0 and T3 (P value $=0.02$ ) (Table I). The amount of mean anchor loss for elastomeric chains was $2.45 \mathrm{~mm}$ with a standard deviation of 0.27 and the mean anchor loss for NiTi coil spring was $1.99 \mathrm{~mm}$ with a standard deviation of 0.19 and was statistically significant between them $(\mathrm{P}$ value $=$ 0.04) (Table II).

\begin{tabular}{|c|c|c|c|c|c|}
\hline variable & group & $\mathrm{N}$ & $\begin{array}{l}\text { Mean in } \\
\mathrm{mm}\end{array}$ & $\begin{array}{l}\text { Std } \\
\text { dev }\end{array}$ & $\mathrm{P}$ \\
\hline \multirow[t]{2}{*}{ Distal mov } & $\begin{array}{c}\text { elastomeric } \\
\text { chains }\end{array}$ & 7 & 3.94 & 0.73 & 0.02 \\
\hline & NiTi & 7 & 4.69 & 0.13 & \\
\hline
\end{tabular}

Table 2: Mean and standard deviation of the anchor loss with elastomeric chain and NiTi coil spring

\begin{tabular}{|c|c|c|c|c|c|}
\hline variable & group & $\mathrm{N}$ & $\begin{array}{c}\text { Mean in } \\
\mathrm{mm}\end{array}$ & $\begin{array}{l}\text { Std } \\
\text { dev }\end{array}$ & $\mathrm{P}$ \\
\hline \multirow[t]{2}{*}{$\begin{array}{l}\text { Anchor } \\
\text { loss }\end{array}$} & $\begin{array}{c}\text { elastomeric } \\
\text { chains }\end{array}$ & 7 & $2.45 \mathrm{~mm}$ & 0.27 & 0.04 \\
\hline & NiTi & 7 & $1.99 \mathrm{~mm}$ & 0.19 & \\
\hline
\end{tabular}

\section{DISCUSSION}

In this study, statistically significant difference was noted in the two groups (elastomeric chains and NiTi coil spring) in the rate of canine retraction between T0 and T3 with the rate of canine retraction being more for NiTi coil spring compared to elastomeric chain (Table I). NiTi coil spring produced a faster rate of canine movement than elastomeric chains (Mohammed et al., 2018) which is in agreement to the present study. A faster tooth movement and a constant force applied by NiTi coil spring was also reported by Barlow et al in his systematic review(Barlow and Kula, 2008).

On evaluating the pre and post retraction records, a definite anchor loss was noted for both the groups with the statistically significant more anchor loss for elastomeric chains ( $p$ value of 0.04). However Chaudhari et al reported more anchor loss for NiTi coil spring compared to that of elastomeric chains(Chaudhari and (Daokar), 2015). Various anchorage considerations like transpalatal arch and also the latest method of using TAD's to minimise anchor loss. Studies done by Davis et al showed that implant supported retraction produced more canine retraction than conventional methods (Davis et al., 2018). Borsos et al suggested that anchorage can be reinforced by making the implant and the molars as one unit(Sharma et al., 2012). 


\section{CONCLUSION}

- NiTi produced a faster rate of tooth movement than elastomeric chains

- elastomeric chains produced a significant amount of anchor loss when compared to NiTi coil spring.

\section{REFRENCES}

Barlow M and Kula K (2008) Factors influencing efficiency of sliding mechanics to close extraction space: a systematic review. Orthodontics \&t craniofacial research 11(2): 65-73.

Charles A, Ramani P, Sherlin HJ, et al. (2018) Evaluation of dermatoglyphic patterns using digital scanner technique in skeletal malocclusion: A descriptive study. Indian journal of dental research: official publication of Indian Society for Dental Research 29(6): 711-715. Chaudhari C and (Daokar) ST (2015) Comparison of rate of retraction and anchorage loss using nickel titanium closed coil springs and elastomeric chain during the en-masse retraction: A clinical study. Journal of Orthodontic Research 3: 129.

Chinnasamy A, Ramalingam K, Chopra P, et al. (2019) Chronic nail biting, orthodontic treatment and Enterobacteriaceae in the oral cavity. Journal of clinical and experimental dentistry 11(12): e1157-e1162.

Davis D, Krishnaraj R, Duraisamy S, et al. (2018) Comparison of Rate of Canine Retraction and Anchorage Potential between Mini-implant and Conventional Molar Anchorage: An In vivo Study. Contemporary clinical dentistry 9(3): 337-342.

Felicita AS (2017a) Orthodontic management of a dilacerated central incisor and partially impacted canine with unilateral extraction - A case report. The Saudi dental journal 29(4): 185-193.

Felicita AS (2017b) Quantification of intrusive/ retraction force and moment generated during enmasse retraction of maxillary anterior teeth using mini-implants: A conceptual approach. Dental press journal of orthodontics 22(5): 47-55.

Felicita AS (2018) Orthodontic extrusion of Ellis Class VIII fracture of maxillary lateral incisor - The sling shot method. The Saudi dental journal 30(3): 265-269.

Felicita AS, Thirumurthi AS and Jain RK (2017) Patient's
Psychological Response to Twin-block Therapy. World Journal of Dentistry 8(4): 327-330.

Graber TM, Vanarsdall RL and Vig K (1994) Current principles and techniques. Mosby-Year Book: 685.

Güray E and Orhan M (1997) 'En Masse' retraction of maxillary anterior teeth with anterior headgear. American journal of orthodontics and dentofacial orthopedics: official publication of the American Association of Orthodontists, its constituent societies, and the American Board of Orthodontics 112(5): 473-479.

Korath AV, Padmanabhan R and Parameswaran A (2017) The Cortical Boundary Line as a Guide for Incisor Re-positioning with Anterior Segmental Osteotomies. Journal of maxillofacial and oral surgery 16(2): 248252.

Krishnan S, Pandian S and Rajagopal R (2017) Sixmonth bracket failure rate with a flowable composite: A split-mouth randomized controlled trial. Dental press journal of orthodontics 22(2): 69-76.

Mohammed H, Rizk MZ, Wafaie K, et al. (2018) Effectiveness of nickel-titanium springs vs elastomeric chains in orthodontic space closure: A systematic review and meta-analysis. Orthodontics \& Craniofacial Research. DOI: 10.1111/ocr.12210.

Pandian KS, Krishnan S and Kumar SA (2018) Angular photogrammetric analysis of the soft-tissue facial profile of Indian adults. Indian journal of dental research: official publication of Indian Society for Dental Research 29(2): 137-143.

Reddy AK, Kambalyal PB, Shanmugasundaram K, et al. (2018) Comparative Evaluation of Antimicrobial Efficacy of Silver, Titanium Dioxide and Zinc Oxide Nanoparticles against Streptococcus mutans. Pesquisa brasileira em odontopediatria e clinica integrada 18(1): e4150.

Sharma M, Sharma V and Khanna B (2012) Mini-screw implant or transpalatal arch-mediated anchorage reinforcement during canine retraction: a randomized clinical trial. Journal of orthodontics 39(2): 102-110. Sharma R, Mittal AK, Sidana A, et al. (2015) Canine retraction in orthodontics: a review of various methods. Med. Res. Chron 2: 85-93. 